\title{
Life cycle sustainability analysis applied to an innovative configuration of concentrated solar power
}

\author{
Blanca Corona $^{1,2}$ (D) Guillermo San Miguel $^{2}$
}

Received: 7 June 2017 / Accepted: 26 November 2018 / Published online: 13 December 2018

(C) The Author(s) 2018

\begin{abstract}
Purpose Life cycle sustainability analysis (LCSA) is being developed as a holistic tool to evaluate environmental, economic and social impacts of products or services throughout their life cycle. This study responds to the need expressed by the scientific community to develop and test LCSA methodology, by assessing the sustainability of a concentrated solar power (CSP) plant based on HYSOL technology (an innovative configuration delivering improved efficiency and power dispatchability).

Methods The methodology proposed consists of three stages: goal and scope definition, modelling and application of tools, and interpretation of results. The goal of the case study was to investigate to what extent may the HYSOL technology improve the sustainability of power generation in the Spanish electricity sector. To this purpose, several sustainability sub-questions were framed and different analysis tools were applied as follows: attributional and consequential life cycle assessment, life cycle cost (LCC) analysis and multiregional input-output analysis (MRIO), and social life cycle assessment (S-LCA) in combination with social risk assessment (with the Social Hotspots Database). Visual diagrams representing the sustainability of the analysed scenarios were also produced to facilitate the interpretation of results and decision making.

Results and discussion The results obtained in the three sustainability dimensions were integrated using a "questions and answers" layout, each answer describing a specific element of sustainability. The HYSOL technology was investigated considering two different operation modes: HYSOL BIO with biomethane as hybridization fuel and HYSOL NG with natural gas. The results indicated that the deployment of HYSOL technology would produce a reduction in the climate change impact of the electricity sector for both operation modes. The LCC analysis indicated economic benefits per MWh for a HYSOL NG power plant, but losses for a HYSOL BIO power plant. The MRIO analysis indicated an increase in goods and services generation, and value added for the HYSOL technology affecting primarily Spain and to a lower extent other foreign economies. The social analysis indicated that both alternatives would provide a slight increase of social welfare Spain.

Conclusions The methodological approach described in this investigation provided flexibility in the selection of objectives and analysis tools, which helped to quantify the sustainability effect of the system at a micro and meso level in the three sustainability dimensions. The results indicated that the innovation of HYSOL power plants is well aimed to improve the sustainability of CSP technology and the Spanish electricity sector.
\end{abstract}

Responsible editor: Alessandra Zamagni

Electronic supplementary material The online version of this article (https://doi.org/10.1007/s11367-018-1568-z) contains supplementary material, which is available to authorized users.

Blanca Corona

b.c.coronabellostas@uu.nl

1 Present address: Copernicus Institute of Sustainable Development, Utrecht University, Heidelberglaan 2, 3854

CS Utrecht, The Netherlands

2 Universidad Politécnica de Madrid, c/José Gutiérrez Abascal 2, 28006 Madrid, Spain 
Keywords Concentrated solar power $\cdot$ Electricity generation $\cdot$ Life cycle assessment $($ LCA $) \cdot$ Life cycle sustainability assessment $($ LCSA) $\cdot$ Multiregional input-output (MRIO) $\cdot$ Social life cycle assessment (S-LCA) $\cdot$ Sustainability

$\begin{array}{ll}\text { Abbreviations } \\ \text { AHP } & \text { Analytic hierarchy process } \\ \text { BIO } & \text { Biomethane } \\ \text { C } & \text { Construction } \\ \text { CED } & \text { Cumulative energy demand } \\ \text { CSP } & \text { Concentrated solar power } \\ \text { D\&D } & \text { Dismantling and disposal } \\ \text { E\&M } & \text { Material extraction and manufacturing } \\ \text { E-LCA } & \text { Environmental life cycle assessment } \\ \text { EPBT } & \text { Energy payback time } \\ \text { G\&S } & \text { Goods and services } \\ \text { IO } & \text { Input-output } \\ \text { LCA } & \text { Life cycle assessment } \\ \text { LCC } & \text { Life cycle cost } \\ \text { LCSA } & \text { Life cycle-based sustainability analysis } \\ \text { MCDM } & \text { Multi-criteria decision making } \\ \text { MRIO } & \text { Multiregional input-output } \\ \text { NG } & \text { Natural gas } \\ \text { O\&M } & \text { Operation and maintenance } \\ \text { PER } & \text { Plan de energías renovables (Spanish renewable } \\ & \text { energies plan) } \\ \text { PTC } & \text { Parabolic trough collectors } \\ \text { SHDB } & \text { Social Hotspots Database } \\ \text { S-LCA } & \text { Social life cycle assessment } \\ \text { TES } & \text { Thermal energy storage }\end{array}$

\section{Introduction}

Over the past three decades, sustainability has grown to become a central element in the agenda of policy makers, businesses, non-governmental organizations, scientists and the civil society as a whole. However, a key issue in this movement remains unresolved: How can we truly measure the sustainability of a given product, service, or technology? Furthermore, how can we incorporate sustainability into decision making in order to ensure the coexistence of humans and nature in productive harmony?

Most authors agree with the Brundtland Report in that sustainability comprises three inter-related dimensions: environment, economy and society (Brundtland 1987). It is also widely accepted that sustainability analyses need to apply a life cycle approach, thus taking into consideration extraction and processing of raw materials, manufacturing, transport activities, utilization of the product by the final user and end-of-life actions, as described in ISO 14040 and 14044. The first systematic methodology aimed at evaluating the sustainability of products and services using a life cycle perspective dates back to 1987 , and it has been attributed to the Oeko-Institut
(Germany) (Kloepffer 2008; Nzila et al. 2012). This framework, originally named Product Line Analysis (Produktlinienanalyse), was refined in subsequent public and private initiatives to become Product Sustainability Assessment (PROSA) (Grießhammer et al. 2007). A fundamental step ahead in this field was attributed to the Coordination Action for innovation in Life Cycle Analysis for Sustainability (CALCAS (2006-2009), a research project financed by the European Commission (Zamagni et al. 2009) that sets the principles of modern life cycle-based sustainability assessments (LCSA). This was followed by other actions aimed at improving, standardizing, testing and promoting the use of this methodology. Noteworthy among these are the EUfunded PROSUITE (2009-2013) project (Blok et al. 2013), the UNEP/SETAC life cycle initiative (UNEP/SETAC 2015), the SETAC Europe 18th LCA Case Study workshop in LCSA (Cinelli et al. 2013) and the special issues on LCSA published by the International Journal of Life Cycle Assessment (Zamagni 2012; Zamagni et al. 2013).

These publications define two alternative approaches to life cycle-based sustainability analysis: Life Cycle Sustainability Assessment, hereafter LCSA (assessment), and Life Cycle Sustainability Analysis, hereafter LCSA (analysis) (Sala et al. 2013; Zamagni et al. 2013). The main proponent of the former is the UNEP/SETAC Life Cycle Initiative whose report "Towards a Life Cycle Sustainability Assessment. Making informed choices on products" describes LCSA (assessment) as the summation of the results obtained from the use (under the same system boundaries) of three independent analysis tools: environmental life cycle analysis (ELCA), life cycle costing (LCC) and social life cycle analysis (S-LCA) (Ciroth et al. 2011). The LCSA (assessment) framework has received criticisms due to its mechanistic approach and lack of flexibility, which obviates the complexity of real systems and the interdependencies that exist between the three sustainability dimensions (Zamagni et al. 2013).

The theory and practice of LCSA (analysis) are described in the various reports produced under the CALCAS project. This methodological approach involves an expansion in the scope of E-LCA with the aim of incorporating into the analysis the economic and societal dimensions of the system, as well as different analysis levels (micro, meso, macro). This has been reported to be more difficult to apply than the LCSA (assessment) approach proposed by UNEP/SETAC as it should take into consideration behavioural relations, sustainability dimensions interactions, time effects, market and demand changes, etc. In addition, LCSA (analysis) provides more flexibility in the selection of analytical tools and provides an integrated framework where the results may be 
evaluated in combination. In this new methodology, the life cycle inventory analysis and the life cycle impact assessment phases described in ISO 14040 are merged together into a single modelling phase where inventory data is converted into a series of sustainability indicators (Heijungs et al. 2009). Thus, LCSA (analysis) may be regarded as a transdisciplinary integration framework of models rather than a model in itself (Guinee et al. 2010).

\subsection{Life cycle-based sustainability assessment methodology}

Owing to its early stage of development, there is still no clear consensus on the practical application of life cycle-based sustainability assessment. This section aims to provide a global vision on how the scientific community has been responding to key methodological issues in the practical application of this methodology. For this purpose, a literature review was carried out using the Web Of Science (WOS) search engine to evaluate the scientific output generated up until September 2015.

A literature search using the strings "Life Cycle Sustainability Assessment" and "Life Cycle Sustainability Analysis" produced 66 items (including peer-reviewed journal articles, conference proceedings and books), whose contents were revised thoroughly. Eleven of these publications were discarded for low quality (the sustainability content was too vague and limited, without quantification or use of recognized tools) or lack of relevance (the study only covered one sustainability dimension) reducing the scope to 55 items. Twenty-eight out of these 55 publications (51\%) were dedicated to define methodological proposals from a theory perspective. The remaining 27 described the practical application of life cycle-based sustainability assessment through a series of case studies on specific products belonging to different sectors (primarily energy generation, construction and waste treatment). Most papers published prior to 2014 dealt with methodology development, while interest shifted towards practical application in subsequent years. A description of all these studies is available in the Electronic Supplementary Material.

Regarding the methodological framework of the case studies reviewed, most of them (48\%) opted for the LCSA (assessment) (corresponding to LCA + LCC + S-LCA). This may be due to a more clearly defined framework of the former methodology and also the widespread acceptance of the UNEP/SETAC Guidelines (Ciroth et al. 2011). The second most widely utilized framework $(15 \%)$ was hybrid LCAinput-output (IO) analysis, an integrated approach that allows using the same economic inventory to evaluate all three sustainability dimensions (Onat et al. 2014). Owing to its topdown approach, the precision of this methodology depends on the quality and disaggregation of regional and multiregional IO databases, which may not always be available and updated for the regions of interest. The LCSA (analysis) approach was only used in 4 of these case studies (7\%), while the remaining 17 publications reviewed (30\% of the total) opted for ad hoc LCSA frameworks, the most common being the tiered approach (Neugebauer et al. 2015; Peukert et al. 2015). ${ }^{1}$

The CALCAS project describes 28 tools suitable to assess different aspects of sustainability including E-LCA, LCC, SLCA, IO, material flow analysis, cost benefit analysis, ecoefficiency analysis, external costs (ExternE), life cycle optimization, etc. (Schepelmann et al. 2008). In the case studies reviewed, the analysis tools most widely used by far are conventional E-LCA for the environmental dimension (in $85 \%$ of the publications evaluated), LCC for the economic dimension (in 55\%) and S-LCA for the social dimension (in 26\%). Sixtythree percent of the publications implemented or proposed the combined use of these three methodologies, as suggested in the UNEP/SETAC Guidelines.

E-LCA is a stablished tool already recognized by the European Commission as best framework for assessing the potential environmental impacts of products (European Commission 2003), while LCC is a mature tool, usually considered for evaluating the life cycle costs of products and services (Hunkeler et al. 2008). However, the adequacy of LCC to evaluate economic sustainability has been questioned by different experts (Jorgensen et al. 2013; Wood and Hertwich 2013) who agree that other indicators (such as value added, labour and capital productivity, or ratio of output per factor input) may provide a more realistically and societyoriented description of economic well-being (Wood and Hertwich 2013). These and other economic performance indicators, like labour costs or international commerce, may be calculated using IO methodology. In the case of the social dimension, the use of ad hoc methods to evaluate the social sustainability is common practice due mainly to the incipient state of development of S-LCA. Central to this evolution stands the UNEP-SETAC Life Cycle Initiative (UNEPSETAC Life Cycle Initiative 2009) and its report Guidelines for Social Life Cycle Assessment of Products. Practitioners often report the need for more research in the development and application of this methodology to improve consistency in the procedures and uniformity in the presentation of results. While $40 \%$ of the revised case studies propose the use of the UNEP-SETAC Guidelines to evaluate social performance, only $7 \%$ of them actually implement this methodology, and this is done in a simplified manner using "workers" as the only impact and stakeholder category.

\footnotetext{
${ }^{1}$ The hybrid LCA-input output frameworks and the ad hoc LCSA frameworks could be considered as examples of analysis tools for LCSA (analysis). However, we chose to classify them differently because the analysis structure does not correspond to the given definition of the LCSA (analysis) framework.
} 
In order to facilitate decision-making, the LCSA needs to be completed with a final step that involves the evaluation, integration and aggregation of results obtained for each of the three sustainability dimensions (as it is also required for ELCA and S-LCA results). The aggregation step is currently a matter of debate. The main difficulty when aggregating the results is the quantification of the relative significance of each sustainability dimension and indicator selected (the weighting process). This problem may be addressed using multi-criteria decision making (MCDM) methods, as they are able to create tailored weighting sets to aggregate diverse indicators. Wang et al. (2009) performed a review of MCDM methods applied to evaluate sustainability in the energy sector and reported the analytic hierarchy process (AHP) as the most popular one. However, since the weighting exercise clearly conditions the objectivity of the final results, some authors prefer to not aggregate the results, but to integrate them into a graphic layout. This may be used directly by decision makers, while keeping open (and sometimes facilitating) the possibility of applying certain weighting sets for results aggregation. The use of graphic methods to integrate results in a transparent and visual manner has been proposed and used by different authors (Finkbeiner et al. 2010; Hardi and Semple 2000; Jesinghaus 2000). Specific diagrams designed for this purpose are the Life Cycle Sustainability Dashboards and the Life Cycle Sustainability Triangle. The former is designed to display, integrate and aggregate results for each analysis dimension using a colour-coded panel and a given weighting set that allows to rank the sustainability of different alternatives (Traverso et al. 2012). The Life Cycle Sustainability Triangle is useful to discern which of two alternatives has higher sustainability on the basis of three different indicators (one for each sustainability dimension) and different weighting sets (Finkbeiner et al. 2010). Of the 27 case studies revised, 33\% did not use any type of aggregation or integration method and $26 \%$ used different types of diagrams to display the results in an integrated way. Most of these diagrams compare the results of different alternatives in relative terms, setting the best and worst results for each alternative as maximum and minimum performance in each area. Only two of those studies applied the Life Cycle Sustainability Dashboard and aggregated the results considering equal weighting factors. The remaining $40 \%$ applied or proposed the use of different types of MCDM for results aggregation, being the AHP the most common (15\%).

Regarding the completeness of the case studies revised, only $30 \%$ of them included the analysis of the three sustainability pillars together with the aggregation of results (using a weighting method) and the final interpretation, while the other $70 \%$ of studies were missing either the analysis on the social/ economic area, and/or the final integration of results. This is an indication of the major challenge behind assessing and integrating all three sustainability areas with a life cycle perspective. More LCSA case studies are needed to facilitate the development of a sound and unified methodological framework, and show the way to future practitioners.

\section{$1.2 \mathrm{Goal}$ of this study}

This article responds to the needs expressed by the scientific community to test the use of life cycle-based sustainability analysis for different products and in different sectors. Due to its innovative approach and potential advances, the study has been based on the premises of the LCSA (analysis) framework, covering the three dimensions (environmental, economic and social) of sustainability. The methodology has been applied to evaluate the sustainability of HYSOL (from HYbrid SOLar), a novel type of hybrid concentrated solar power (CSP) plant designed to operate using both solar energy and auxiliary fuels. The incorporation of high capacity thermal energy storage (TES) and the use of aeroderivative turbines with thermal recovery for the integration of auxiliary fuels has been reported to improve efficiency, dispatchability and firmness in the generation of power, compared with conventional CSP. The interest of this paper lays not only on the sustainability results obtained for the HYSOL technology but primarily on the operationalization of LCSA (analysis) framework. These include definition of structural concepts (general approach, definition of objectives, analysis tools and choice indicators for each sustainability dimension, communication of results), practical issues such as the combination of different analysis levels and integration of different sustainability dimensions, and the definition of system boundaries for each sustainability dimension.

\section{Methodology proposal and application to a case study}

This section describes the life cycle-based sustainability analysis of the hybrid HYSOL solar power technology using the LCSA (analysis) approach. The proposal builds upon the operational framework proposed by $\mathrm{Hu}$ et al. (2013), which follows the provisions described in the CALCAS project (Heijungs et al. 2009; Zamagni et al. 2009). The proposed analysis framework is outlined in Fig. 1 and consists of three interrelated and iterative phases: (1) goal and scope definition, (2) modelling and application of tools, and (3) interpretation of results. Methodological and practical aspects in the application of each of these phases are discussed below.

The investigation has been carried out in the context of the HYSOL project (CP 308912), funded by the European Commission (EC) under the FP7-ENERGY-2012-1 program and aimed at developing a hybrid power plant which may operate using solar energy and/or auxiliary gas fuels (in the form of biomethane or natural gas) for improved efficiency 
Fig. 1 Three steps of the proposed framework for life cycle sustainability assessments
1. Goal and scope definition

1.1 Broad System definition 1.2 Making scenarios 1.3 Sustainability questions and tools
2. Modelling

2.1 Environmental dimension

2.2 Economic dimension making

\section{Results interpretation}

3.1 Sustainability quantification 3.2 Interpretation and decision 2.3 Social dimension and dispatchability. The aim of applying LCSA (analysis) to this investigation is twofold: first, to evaluate the practical value of the methodology in the sustainability analysis of a given technology; and second, to determine its usefulness in the process of decision making under a public management context.

\subsection{Goal and scope definition}

The goal and scope definition phase of this evaluation includes three steps: (1.1) broad system definition, (1.2) definition of system alternatives and scenarios, and (1.3) defining sustainability sub-questions.

\subsubsection{Broad system definition}

The Broad system definition step is aimed at providing a comprehensive description of the system under consideration in order to define the problems and the main decisions at stake, to identify key relations (synergies, conflicts, compensation, etc.) between material elements, between processes and actors that make out the system and also between the three sustainability dimensions (environment, economy and society). This step should also indicate the main goal of the investigation, which take the form of a "main sustainability question." This question needs to be clear and unambiguous, specifying the context of the investigation, the functions that need to be fulfilled by the analysis and the level of the analysis (micro for project/product, meso for activity sector and macro for the global economy) (Heijungs et al. 2009).

The HYSOL technology sets the technical basis for a new concept of CSP plants designed to operate in hybrid mode using a gas auxiliary fuel that is integrated into the system using combined cycle technology. In this configuration, the exhaust gases generated in the aeroderivative gas turbine are directed to an innovative heat recovery system (HRS) designed to heat the molten salts contained in a thermal energy storage (TES) system. The specific characteristics of the HYSOL plant (regarding steam and gas turbines capacities) and its operating strategy (in terms of solar fraction) may be adapted to the availability of the solar resource and the regional/national demand curve in order to generate electricity on demand at lower costs. The HYSOL technology achieves a higher energy efficiency than conventional CSP plants deployed in Spain. Further details about the HYSOL technology and its potential in the Spanish energy system may be found in San Miguel et al. (2015) and Servert et al. (2015). The function of the HYSOL system is, hence, to supply electricity to the grid in a dispatchable manner. The functional unit is $1 \mathrm{MWh}$ of electricity poured into the grid.

The central goal of this LCSA derives from providing a comprehensive response to the following main sustainability question: To what extent may the HYSOL technology improve the sustainability of power generation in the Spanish electricity sector? The response to this question should cover all three sustainability dimensions: environment, economic and social. A supplementary goal is also set in the form of a secondary sustainability question: In the context of a future Spanish renewable energy plan, which CSP technology should be favoured considering sustainability criteria? This second part of the analysis should aim to facilitate decision makers in the selection of the most sustainable solar thermal power technology, including HYSOL and conventional CSP.

Table 1 provides information about the technical characteristics of the two solar thermal power plant concepts considered in this investigation. The HYSOL plant is based on dry cooling central tower CSP technology designed to operate in hybrid mode using a 100-MWe steam turbine and an 80-MWe gas turbine for the combustion of auxiliary gas fuel. The plant also incorporates a molten salt TES system based on two-tank indirect technology yielding $14 \mathrm{~h}$ of full capacity storage. When adapted to the solar resource and demand curve of the Spanish electricity market, the solar fraction of the HYSOL plant represents $45 \%$ of the total energy input, consuming $3.40 \times$ $10^{9} \mathrm{MJ} /$ year of auxiliary gas fuel for a total power output of 799,437 MWh/year. This investigation considers two options for HYSOL technology depending on the nature of the auxiliary fuel: biomethane (referred to as $H Y S O L$ $B I O$ ) or natural gas (referred to as HYSOL NG), the former option resulting in the generation of $100 \%$ renewable electricity.

The HYSOL technology has been tested for sustainability against a second solar plant concept, which represents the CSP technology most widely deployed in Spain as follows: 50 MWe wet cooled based on parabolic trough collectors (PTC) with 7.5-h capacity TES and hybrid mode operation with $15 \%$ natural gas. The natural gas is burnt using an open cycle boiler parallel to the solar field. Due to its reduced capacity and higher solar fraction $(85 \%)$, this plant consumes significantly less natural gas $3.37 \times 10^{8}$ and generates less electricity $(194,677 \mathrm{MWh} /$ year) than the HYSOL plant. A key difference between HYSOL and conventional CSP technology relates to the improved dispatchability (i.e. capacity to 
Table 1 Technical characteristics of the concentrated solar plants (HYSOL and conventional CSP) considered in the LCSA

\begin{tabular}{lll}
\hline Characteristics of the power plant & HYSOL $^{\mathrm{a}}$ & CSP PTC \\
\hline Direct normal irradiation (kWh/m ${ }^{2} /$ year) & 2086 & 2086 \\
Installed capacity (MWe) & 180 & 50 \\
Heliostats/solar collectors (units) & 9151 & 624 \\
Aperture $\left(\mathrm{m}^{2}\right)$ & $1,321,174$ & 510,120 \\
Tower height (m) & 201 & - \\
Thermal storage capacity (h) & 14 & 7.5 \\
Annual electricity poured into the grid (MWh/year) & 799,437 & 194,677 \\
Solar fraction (\%) & 45 & 85 \\
Consumption of fuel (MJ/year) & $3.40 \times 10^{9}$ (Biomethane) & $3.37 \times 10^{8}$ (Natural gas) \\
Direct water consumption (O\&M $\mathrm{M}^{\mathrm{a}}$ phase) (m²/year) & $1.16 \times 10^{5}$ & $1.11 \times 10^{6}$ \\
Cooling system & Dry & Wet \\
\hline
\end{tabular}

${ }^{\text {a }}$ HYSOL BIO when using biomethane as auxiliary gas and HYSOL NG when using natural gas generate on demand) of the former. This essential difference in the functionality of the systems was also considered in the impact evaluation and discussion of results.

\subsubsection{Making scenarios}

The Making scenarios step involves describing the different environmental, social, economic and/or technology alternatives that will be used for the construction of the sustainability models (e.g. deployment scenarios, alternative plant designs, operating conditions, etc.). This step provides a comparative basis for decision making, and it is especially relevant in prospective analyses considering future scenarios.

The scenarios contemplated in this investigation refer to the deployment of CSP technology in Spain in order to fulfil the objectives set in The Spanish National Plan for Renewable Energies (Plan de Energías Renovables (PER)) for period 2011-2020 (IDAE 2011). This involves the installation of $2.5 \mathrm{GW}$ of CSP, which could be supplied in the form of conventional CSP or HYSOL plants. Considering that one HYSOL power plant located in Spain would produce $800 \mathrm{GWh} /$ year of electricity and one standard CSP PTC plant produces $195 \mathrm{GWh}$ /year (according to the operation conditions indicated in Table 1), fulfilling the objectives of PER for 2020 would involve the installation of 12 HYSOL plants or 48 CSP PTC plants.

\subsubsection{Defining sustainability sub-questions}

Once the system has been described and the alternative scenarios have been defined, the next step involves framing the sustainability sub-questions that will connect the research problem (main broad sustainability question) with specific objectives that are measurable and have a more restricted scope. The sustainability sub-questions will define the concrete assessment steps in each sustainability dimension, and also the specific quantification tools needed and their analysis level (micro, meso or macro). The response to the main sustainability question derives from the responses generated to the sub-questions, which are also the basis for the conclusions and recommendations of the assessment (Heijungs et al. 2009).

The sustainability sub-questions posed in this investigation are described in Table 2, together with the tools required to provide an answer. The main sustainability question has been broken down into 11 sub-questions, each one addressing a specific aspect of the environmental, economic and social dimensions relevant to the goal of the analysis and the technology under study. The response to each of these questions requires the calculation of at least one quantitative indicator. The scope for most of these sub-questions adheres primarily to micro (project) level analysis, while questions $c$ and $h$ relate to meso (electricity sector) level issues, and questions $f$ and $g$ relate to macro level (Spanish economy).

Regarding the environmental dimension, questions $a$ and $b$ are aimed at defining the environmental performance of the HYSOL technology, and compare it with conventional CSPPTC. E-LCA was the tool selected to provide a quantitative response to these two questions, since it is the most widely accepted methodology to evaluate the environmental dimension of goods and services (European Commission 2003). Question $b$ is aimed at evaluating the consequences of integrating the HYSOL technology into the Spanish electricity sector. Responding to this question requires the application of a consequential approach that takes into consideration not only the environmental performance of the solar technology but also changes in the electricity market resulting from the displacement of existing technologies.

Questions $d, e$ and $f$ are aimed at describing the economic performance of the two technologies under consideration: HYSOL and CSP-PTC. Two different analysis tools were used in combination to provide a comprehensive description of this sustainability dimension: LCC was used to quantify the economic performance of the system from the perspective of the owner of the power plant, and multiregional input-output 
Table 2 Sustainability sub-questions framed to define specific goals of the sustainability analysis of the CSP technologies, as defined by the goal and scope, together with their analysis level and the analysis tool proposed

\begin{tabular}{|c|c|c|}
\hline Environmental dimension & Tool & Selected indicators \\
\hline $\begin{array}{l}\text { a. What is the life cycle environmental impact } \\
\text { of producing electricity with HYSOL technology? }\end{array}$ & Attributional E-LCA & $\begin{array}{l}\text { - Climate change (kg CO2 eq/MWh) } \\
\text { - Water stress (m3/MWh) }\end{array}$ \\
\hline $\begin{array}{l}\text { b. What changes are expected in the environmental } \\
\text { impact of the electricity sector as a result of introducing } \\
\text { HYSOL technology? }\end{array}$ & Consequential LCA & $\begin{array}{l}\text { - EPBT (months) } \\
\text { - Single score environmental impact } \\
\quad(\mathrm{pt} / \mathrm{MWh})\end{array}$ \\
\hline $\begin{array}{l}\text { c. Is the environmental impact of HYSOL technology } \\
\text { lower than conventional CSP plants? }\end{array}$ & Consequential E-LCA & \\
\hline Economic dimension & Tool & Selected indicators \\
\hline $\begin{array}{l}\text { d. What is the life cycle cost of producing electricity } \\
\text { using HYSOL technology, from the perspective } \\
\text { of the owner of the power plant? }\end{array}$ & LCC & $\begin{array}{l}\text { - Life cycle cost }(€ / \mathrm{MWh}) \\
\text { - Cost balance }(€ / \mathrm{MWh})\end{array}$ \\
\hline $\begin{array}{l}\text { e. Is the life cycle cost of HYSOL electricity lower } \\
\text { than that of conventional CSP plants? }\end{array}$ & LCC & \\
\hline $\begin{array}{l}\text { f. What is the effect of HYSOL life cycle on the } \\
\text { global generation of goods and services (G\&S), and value } \\
\text { added? }\end{array}$ & MRIO & $\begin{array}{l}\text { - G\&S (€/MWh) } \\
\text { - Value added }(\%) \\
\text { - Multiplier effect }\end{array}$ \\
\hline $\begin{array}{l}\text { g. What changes are expected in the global generation } \\
\text { of goods and services, and of value added as a result } \\
\text { of introducing the HYSOL technology into the electricity } \\
\text { market? }\end{array}$ & MRIO (net results) & $\begin{array}{l}\text { - Net G\&S (€/MWh) } \\
\text { - Net value added }(\%)\end{array}$ \\
\hline Social dimension & Tool & Selected indicators \\
\hline $\begin{array}{l}\text { h. Does HYSOL technology promote employment } \\
\text { creation in the Spanish electricity sector? }\end{array}$ & MRIO (net results) & Employment generated (person-year) \\
\hline $\begin{array}{l}\text { i. What are the social risks of the HYSOL } \\
\text { technology supply chain? }\end{array}$ & S-LCA (with SHDB) & Weighted social risks (pt) \\
\hline $\begin{array}{l}\text { j. Is the employment generation and social risk } \\
\text { of HYSOL electricity lower than that } \\
\text { of conventional CSP plants? }\end{array}$ & $\begin{array}{l}\text { MRIO (net results), S-LCA (with } \\
\text { SHDB) }\end{array}$ & $\begin{array}{l}\text { Net employment generated (h/MWh) } \\
\text { Social risks (pt/MWh) }\end{array}$ \\
\hline $\begin{array}{l}\text { k. Does the HYSOL technology improve social } \\
\text { conditions in Spain at the sector level? }\end{array}$ & S-LCA & Company social performance (pt/MWh) \\
\hline
\end{tabular}

SHDB Social Hotspots Database

(MRIO) analysis was used to evaluate the impact of the solar plants on a series of macro-economic indicators affecting the national and international economies. The scope of subquestion $g$ covers the economic effects of the technology in the electricity sector. This requires including in the analysis the displacement of existing technologies as considered in the environmental dimension. These economic effects were evaluated using MRIO Analysis methodology with a net approach (Corona et al. 2016a).

Regarding the social dimension, questions $\mathrm{h}$ and $\mathrm{i}$ are aimed at describing the potential social risks and employment generated (both local and national) by the solar system. Question $\mathrm{j}$ is aimed at comparing the aforementioned social issues with a conventional CSP plant, while the last question (k) is aimed at investigating if the social performance of the companies involved in the HYSOL supply chain would improve the social conditions (labour rights, health and safety, fairness of relationships, socioeconomic effects in several stakeholders) in Spain. MRIO analysis was also used to calculate employment generation associated with the life cycle of the solar technologies. Additional aspects of the social dimension related to human welfare were evaluated using SLCA methodology. A more comprehensive discussion about the application of this methodology for the analysis of the solar plants (including a novel classification and characterization method) is found in Corona et al. (2017).

\subsection{Modelling and application of analysis tools}

This second phase of the LCSA (analysis) relates to the modelling of the systems under investigation. This is done using the analysis tools proposed in Sect. 2.1.3 to produce a series of quantitative indicators that describe the sustainability of the scenarios. The analyses were based on comprehensive economic, materials and processes inventory of the solar technologies (both HYSOL and conventional CSP-PTC), covering the following cradle-to-gate life cycle phases: material extraction and manufacturing (E\&M), construction (C), operation and maintenance $(\mathrm{O} \& \mathrm{M})$, and dismantling and disposal (D\&D). Primary inventory data (including plant components, infrastructures, construction, auxiliary systems, operation and maintenance, water and fuel consumption, power generation, 
etc.) were provided by the engineering companies IDie S.L. and ACS-COBRA S.A., both specialized in CSP technology and based in Madrid (Spain). Primary inventory data for the biomethane system were supplied by Biogas Fuel Cell S.L., based in Asturias (Spain). The end-of-life of the materials employed in the construction of the energy systems were modelled considering existing waste management scenarios in Spain. More details about data selection and modelling choices for each of the sustainability dimensions are described in the following sections.

\subsubsection{Analysis of the environmental dimension}

The E-LCA models were built and run in SimaPro 8.0.3 using the Recipe Midpoint and Endpoint Europe (H perspective) methods for the classification, characterization, normalization and weighting of environmental impacts (Goedkoop et al. 2009). This evaluation method was chosen as it is a wellestablished method containing all the environmental categories relevant for the technology, and covered the geographical and temporal scope of the analysis. The cumulative energy demand (CED) v9 method (Hischier et al. 2010) was applied to determine primary energy demand for the calculation of EPBT. Water scarcity was calculated using the water stress index, taking into account direct water consumption during the operation and maintenance of the solar plants and regional water stress indices as published by Pfister et al. (2012). Ecoinvent v. 3 allocation default and consequential approaches (Weidema et al. 2013) were used to model secondary inventory data on the following systems: processing of raw materials, manufacturing of plant components, construction activities, waste treatment and transport processes. The end-of-life scenario for the power plant materials assumed recycling as main treatment for most of the materials ( $80 \%$ for iron, $90 \%$ for aluminium, $95 \%$ for copper and $60 \%$ for plastic, paper, glass, bricks and concrete), except for wood and the inseparable fraction of the aforementioned materials (100\% incineration or landfill, depending on the material) and for oils and molten salts (100\% landfill for hazardous waste). System expansion was considered for the allocation of impacts to recycled materials. Full information about additional assumptions, methodology details and life cycle inventories of the systems under study have been published in (Corona et al. 2014, 2016b; San Miguel et al. 2016).

Four specific indicators were selected to represent the environmental profile of the solar technologies in the decision making stage of the LCSA (corresponding with the secondary goal of the study stated in section 2.1.1): carbon footprint, energy payback time (EPBT), water stress and single score environmental impact (Recipe 2008 Endpoint weighted score). The first two were chosen attending to international concerns regarding climate change and depletion of nonrenewable energy resources. Water stress was selected to represent concerns regarding the potential incompatibility of geographic locations with high solar radiation and limited freshwater resources. The single score indicator was chosen as it provides a comprehensive indication of the weighted impacts on human health, quality of ecosystems and depletion of resources, using a damage-oriented approach (endpoint).

Two different LCA approaches were applied to respond the sustainability sub-questions: attributional and consequential. Attributional LCA is the preferred approach to answer questions related to the environmental footprint of the system without interacting with other systems (Wolf et al. 2010). This approach was selected to determine the main environmental impacts of the system and points of improvement at a micro level (the generation of electricity in a single power plant), answering to question a.

Consequential E-LCA was applied to calculate those indicators intended to be used for comparative purposes (as in questions $\mathrm{b}$ and $\mathrm{c}$ ). The consequential approach takes into account changes in the market derived from the demand of one functional unit of the system and therefore is useful to evaluate the impact of decisions, such as choosing between two products or whether promoting one technology instead of others, and it is the recommended approach when considering a meso/macro level analysis (Wolf et al. 2010). In this case, the consequential approach provides an assessment of the consequences of deploying HYSOL technology into the electricity sector.

Application of the consequential approach required identifying the technologies that would be displaced by the production and provision of CSP electricity in the Spanish electricity market. According to consequential modelling procedures, the marginal technology is the unconstrained technology with highest short-term or long-term production costs (depending if the market trend is decreasing or increasing in demand) (Mathiesen et al. 2009). The Spanish electricity market follows a liberalized marginal system where the price is determined hourly by the most expensive megawatt-hour fulfilling the demand. The market behaviour is not only governed by technology costs and energy resource availability but also by regulations and complex corporate strategies aimed at maximizing benefits. The multiple variables affecting the electricity mix in the Spanish electricity market complicate the search for fully unconstrained and elastic technologies. Therefore, the marginal technology in this case was determined by studying the electricity market records (published by the Operator of the Electricity Market in Spain) containing the actual marginal technologies with highest production costs (the ones fixing the electricity price) each hour over a 1-year period. These technologies were aggregated in the form of an annual average mix of technologies and used as the short-term marginal technology. The resulting average mix of marginal technologies for the HYSOL scenarios was as follows: hydroelectric $36.5 \%$, natural gas combined cycle $5.3 \%$, coal thermal 
$27.1 \%$, wind $13.7 \%$, conventional CSP $1.4 \%$, pumpedstorage $14 \%$ and imports from France 1.9\%. Further details about the methodology regarding the estimation of the mix of marginal technologies for HYSOL and CSP power plants are described in San Miguel et al. (2016) and Corona et al. (2016a).

\subsubsection{Analysis of the economic dimension}

LCC analysis and MRIO analysis were used to estimate the economic dimension of the HYSOL technology (in its two alternatives HYSOL BIO and HYSOL NG) and the CSP PTC technology. LCC methodology was used to quantify economic effects at a micro analysis level (technology) (for questions $d$ and $e$ ), and MRIO with a net approach was used to evaluate consequences at a meso and macro analysis level (sector and global) (for questions $\mathrm{f}$ and $\mathrm{g}$ ). The net approach for the MRIO analysis consisted in considering the displacement of other electricity technologies as a result of introducing solar power, therefore accounting for the net economic effects at a sector level (solar technology minus displaced energy technologies) (Corona et al. 2016a).

Four indicators were selected to represent the economic dimension in the decision making stage of the LCSA: life cycle cost, costs balance per functional unit, net value added and multiplier effect. The life cycle cost represents the summation of all the costs incurred in the life cycle of the power plant from the perspective of the power plant owner, while the cost balance per functional unit gives an indication of the profits yielded from selling the electricity (i.e. the balance between the costs and the revenues). Value added in input-output analysis is defined as gross output at basic prices minus the cost of intermediate goods and services at purchasers' prices (including wages, profits and net taxes on production) (Timmer et al. 2012). The sum of all value added produced by every industry within a given economy equals its gross domestic product (Timmer et al. 2015). In this study, the indicator net value added represents the difference between the value added generated in Spain by all the industries affected by the demand of good and services (G\&S) generated by the solar power plants and the value added lost due to the displacement of other technologies by the deployed solar plants. Therefore, the higher the net value added, the higher the economic growth generated in Spain by the project. The multiplier effect gives a measure of indirect economic activities caused by the demand of a specific set of G\&S, in this case those generated by the deployment of the solar plants. The multiplier effect in this study gives a measure of the amount of indirect and induced G\&S produced globally due to the direct demand of G\&S from the solar power plants.

The first two indicators represent the cost and profitability of the technology from the perspective of the power plant owner (and seller of electricity), while the latter two represent the generation of economic welfare affecting the economic prosperity of society as a whole (value added for Spain, and multiplier effect for the whole world). These indicators were chosen due to their ability to represent the two dimensions of economic sustainability: profitability from the company's private perspective and economic gains for the benefit of society as a whole (see economic debate mentioned in Sect. 1.1 and discussed by Jorgensen et al. 2013; and Wood and Hertwich 2013).

In order to maintain coherence in the integration of sustainability results, the system boundary adopted in these analyses was similar to that employed in the E-LCA. The main differences are related to the inclusion in the economic analysis of project management activities such as project engineering, bank financing services and insurances, which are relevant to economic and social analyses but not for environmental analyses. Another difference with respect to E-LCA is the use of discounting rates. Economic impacts are discounted to account for the value of money across time (associated with costs of opportunities, investment risks and inflation), while environmental impacts are typically not discounted because environmental impacts in the future should not be less important than present impacts.

The economic inventories used in this analysis covered purchase costs of power plant components (E\&F phase), construction costs (C phase), operation and maintenance costs (O\&M phase), and dismantling and disposal costs (D\&D phase). The economic analyses assumed that $70 \%$ of the capital investment was covered by a 20 -year fixed-rate bank loan and the remaining $30 \%$ by equity. Cash flows were actualized assuming a $6.698 \%$ discount rate, calculated as the weighted average cost of capital (WACC) of the bank loan (70\% investment at $6.398 \%$ ) and the expected return for the investor (30\% investment at $7.398 \%$ ). Revenues from electricity sales were calculated considering the amount of power poured into the network, the average pool price of electricity in Spain (53.08 $€ / \mathrm{MWh}$ ), as reported by the national Ministry of Industry, Energy and Tourism (Orden IET/1045/2014 2014), and also financial incentives associated with power generation from renewable energy resources (Real Decreto 413/2014 2014). Full information about the methodology, data sources and results of the LCC and MRIO analyses conducted on the solar plants may be consulted at Corona et al. (2016a, c).

\subsubsection{Analysis of the social dimension}

MRIO analysis and S-LCA were used to quantify the social dimension of the solar power technologies considered in the LCSA. The three indicators selected to facilitate decision making in this field were the following: employment creation, social risk and social performance of the promoter. These indicators were chosen for their ability to represent social issues of interest not only for Spanish 
policy makers (employment creation and social performance of the promoter in Spain) (as indicators for questions $h$ and $k$ ) but also for the whole supply chain (social risk) (for questions $i$ and $j$ ). Employment creation includes both direct and indirect jobs derived from the economic flows generated throughout the life cycle of the solar plants. Direct jobs represent the labour resources necessary to provide the direct demand for G\&S (i.e. jobs created by direct suppliers of G\&S to the power plants), while indirect jobs are defined as the labour resources necessary to provide the indirect demand of G\&S (i.e. jobs generated by suppliers of the suppliers). The social risk is a numerical indicator representing the social problems per functional unit that may arise as a result of economic transactions occurring along the value chain of the technologies considered. This indicator was calculated using the Social Hotspots Database (SHDB) (BenoitNorris et al. 2013), which was used to model the global supply chain of all the products and services associated with the life cycle of the solar plants.

Based on the results of the hotspots analysis, a sitespecific assessment covering the construction (C), Operation and management (O\&M), and Dismantling (D) phases was conducted to assess the relevance of the main social issues raised by the risk assessment. The result of this site-specific assessment is referred to as the "social performance of the promoter," an indicator taking into consideration the social records of the organizations involved in the life cycle of the energy systems, primarily in the construction and operation of the solar plants in Spain. This assessment was performed following the UNEP/ SETAC guidelines (UNEP-SETAC Life Cycle Initiative 2009) and considering the following impact categories: "labour rights and decent work," "health and safety," "cultural and natural heritage," "fair relations" and "socio-economic sustainability." As explained in Corona et al. (2017), these categories were represented by 24 indicators and assessed by considering the performance of the promoter company (involved in the construction and operation of the solar plants) in comparison to average social performance in Spain. Further information on the subcategories and indicators considered can be found in the Electronic Supplementary Material. Equal weighting was assumed for every indicator. The only company considered in this analysis is a trans-national engineering firm based in Spain with strong presence in the construction and energy sectors that acted as promoter and operator of the solar technologies. For the purpose of this investigation, it has been assumed that the same company would undertake the three projects considered (HYSOL BIO, HYSOL NG and CSP PTC). Full details regarding methodology, indicators and results in the social analysis of the solar plants can be found in Corona et al. (2017).

\subsection{Interpretation of results and decision-making}

In the third and last phase of the LCSA (Interpretation of results and decision making), the results obtained from the application of the analysis tools in the modelling stage are interpreted to describe the sustainability performance of the system under study. These results are defined by the answers to the sustainability questions stated in the goal and scope step, and would be used by decision makers to ascertain the sustainability of the system and guide them in the selection of the best alternative and/or scenarios. This investigation proposes that this final phase is carried out in two steps: (i) quantification of sustainability and (ii) decision-making support.

The first step, quantification of sustainability, takes the form of a series of numerical values and qualitative statements produced in response to each of the sustainability questions and sub-questions posed in the first stage of the LCSA (analysis). These responses provide information about the interpretation and significance of results, methodological limitations and uncertainties.

The second step, decision making, involves evaluating choices and proposing recommendations based on the results generated in the previous step. Weighting and aggregation of the different sustainability criteria involved in the decision process should preferably be avoided, as weighting factors are based on value choices and aggregation of results would eventually lead to a loss of information. However, when the purpose of the sustainability analysis is to compare between alternative products or scenarios, aggregation and weighting of results would probably be useful for the decision maker. As stated in Sect. 1.1, this can be assisted with MCDM methods such as AHP, which converts the preferences of the stakeholders into numerical values, resulting in a final score for each alternative (Saaty 1990). The application of the AHP method would require the participation of the stakeholders affected by the system (in this case, representatives of the private electricity sector, public administration, labour unions, human rights organizations and environmental groups). Since weighting of results is based on value choices, the sensitivity of different weighting sets should be explored before making a final decision.

The application of MCDM methods can be facilitated by representing the sustainability results in a clear, simple and unambiguous way, easy to understand by decision makers. Different types of graphic representations can be used for this purpose, which need to consider the following issues:

- They should facilitate the visualization of the best alternative for each sustainability indicator without the need for complex instructions.

- They should contain the quantitative value as calculated for each of the indicators considered in each sustainability dimension. 
Fig. 2 Colour-coded diagrams (sustainability crowns) and colour scale employed to represent the sustainability performance of the energy systems

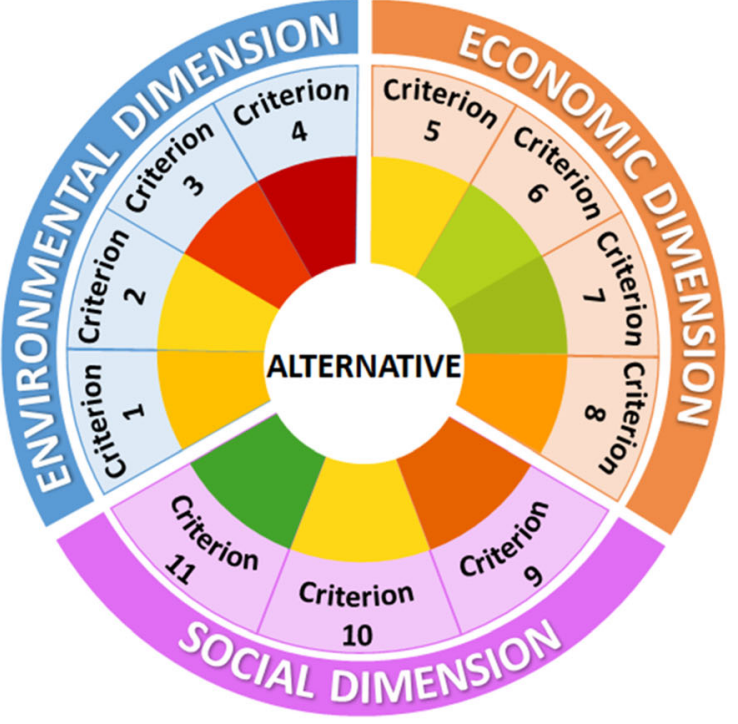

- Every indicator should be represented with the same relevance, since the relative weight for each indicator would be assigned by the decision makers (if needed).

- They should provide performance information using internationally accepted codes (e.g. colour scale of traffic lights).

- The colour scale should represent relative differences for each indicator among alternatives. For example, a significant difference in one indicator should be clearly identifiable than a less marked difference (e.g. 200\% higher versus $10 \%$ ).

Figure 2 illustrates the diagram (sustainability crown) proposed in this investigation to facilitate decision making. The information for each alternative is laid out in a circular diagram divided into three equal size sectors, each one corresponding to a sustainability dimension. The indicators/ criteria selected for each dimension are represented within their corresponding sectors, together with their absolute numeric value and their relative colour, which represents its performance compared to the other alternatives.

The colour code and the relative value (\%) assigned to each indicator represents its percentage difference relative to the average of this indicator in all the alternatives/scenarios evaluated, as determined in Eq. (1), where the average value is calculated by the arithmetic mean of every alternative values:

$\%$ change $=\frac{\text { Alternative value }- \text { Average value }}{\text { Average value }}$

The colour scale follows the traffic light code where green represents superior and red inferior than average, in terms of sustainability performance. Yellow colour ( $0 \%$ change) is assigned to values that are similar to the average of the corresponding indicator. The relative $\%$ change may be positive or negative depending on the direction of the indicator. In those indicators where a lower absolute value represents better sustainability performance (e.g. $\mathrm{kg} \mathrm{CO}$ eq in carbon footprints), the colour of the indicator should turn from yellow to green if the $\%$ change is negative. However, if the $\%$ change is positive, the colour of the indicator turns from yellow to red representing worse performance than the average. An indicator performing $100 \%$ better than average is assigned intense green and $100 \%$ worse receives intense red. The colour grade assigned to each relative \% value is also described in Fig. 3. The colour scale is inverted in indicators where higher absolute values represent improved sustainability (e.g. number of employments).

The main difference of the sustainability crowns with respect to the Life Cycle Sustainability Dashboard (Traverso et al. 2012) is that the former compare the sustainability performance between alternatives instead of to an average country value. This is especially relevant for micro level indicators where no country average is available or applicable. Also, the crowns do not provide a final aggregated sustainability value, since the purpose is to facilitate aggregation and weighting in decision making processes. Finally, the crowns provide more flexibility to include different indicators in the diagram that would not fit into the dashboard framework.

\section{Results, interpretation and decision making}

This section describes the short versions of the responses given to each of these questions. ${ }^{2}$ Extended versions of these

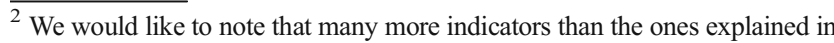
these answers were calculated, but we only focus on the final ones required to assist in the decision making process (answering the secondary sustainability question).
} 

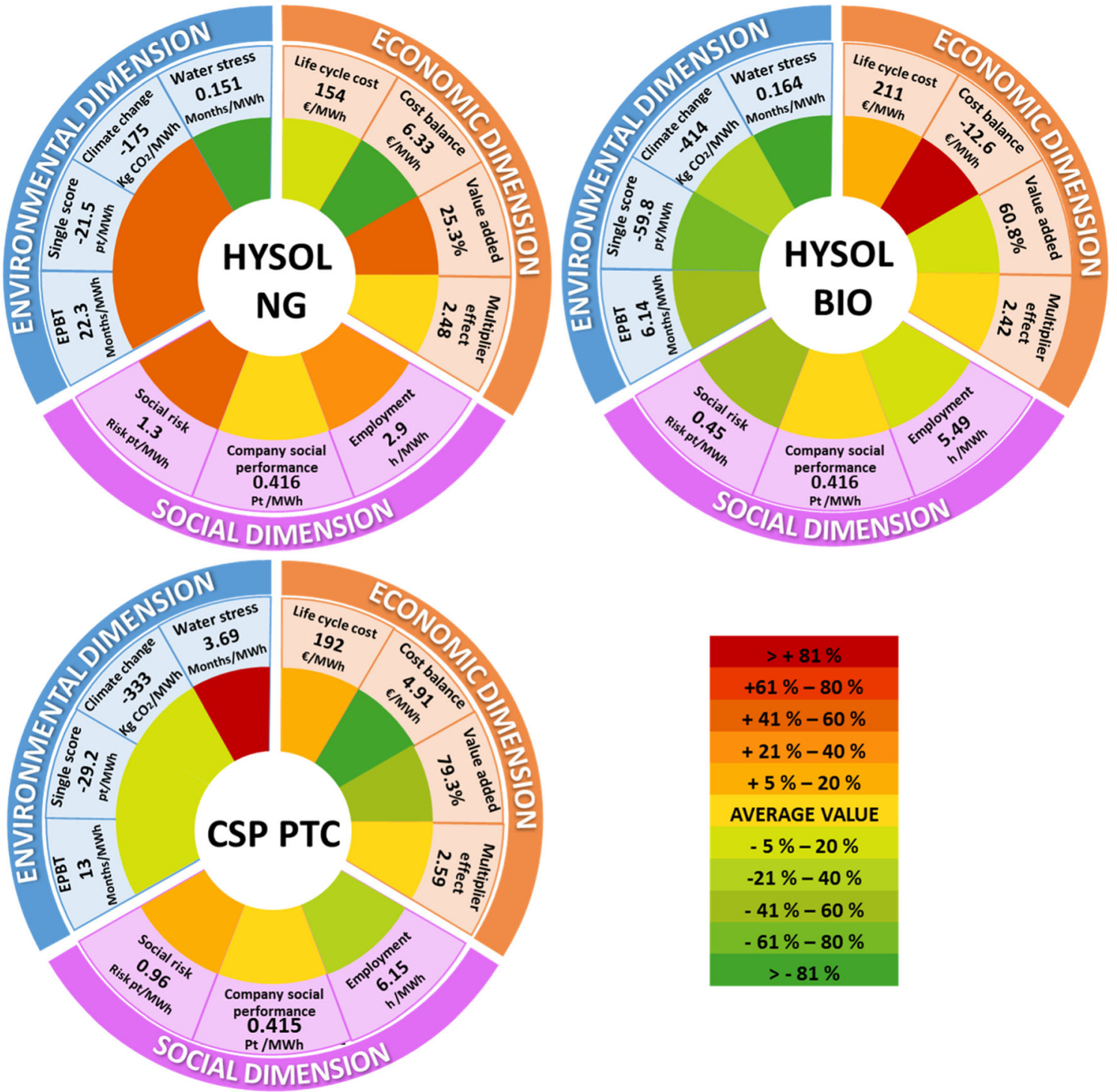

Fig. 3 Sustainability crowns describing the performance of alternative solar power technologies (HYSOL BIO, HYSOL NG and CSP PTC)

responses and calculation details for every indicator may be consulted in the dissertation thesis of Corona Bellostas (2016) and in San Miguel et al. (2016).

\subsection{Environmental dimension}

a. What is the life cycle environmental impact of producing electricity with HYSOL technology? Table 3 illustrates the results for the four selected environmental sustainability indicators (mentioned in Sect. 2.2.1) of the hybrid solar thermal power plant, considering two technology scenarios: operating with biomethane (HYSOL BIO) or natural gas (HYSOL NG). These results were calculated using attributional E-LCA.

b. What changes are expected in the environmental impact of the electricity sector as a result of introducing the HYSOL technology? The environmental impacts associated with the production of electricity in the HYSOL plant (as calculated

Table 3 Potential environmental impacts of the HYSOL technology in the four environmental indicators (attributional approach) selected in the LCSA

\begin{tabular}{|c|c|c|c|c|c|}
\hline & & $\begin{array}{l}\text { Climate change } \\
(\mathrm{kg} \mathrm{CO} 2 \text { eq/MWh) }\end{array}$ & $\begin{array}{l}\text { Water stress } \\
\left(\mathrm{m}^{3} / \mathrm{MWh}\right)\end{array}$ & EPBT (months) & $\begin{array}{l}\text { Single score environmental } \\
\text { impact (pt/MWh) }\end{array}$ \\
\hline \multirow[t]{2}{*}{ HYSOL } & $\mathrm{BIO}$ & 45.9 & 0.164 & 6.1 & 8.27 \\
\hline & GN & 294 & 0.151 & 22 & 35.2 \\
\hline
\end{tabular}


using attributional E-LCA and considering the four indicators described above) were found to be lower than those calculated for the mix of marginal technologies that would be displaced as a result of the deployment of this technology in Spain. Hence, the consequence of supplying HYSOL electricity to the Spanish electricity market would be beneficial to its environmental performance as a whole. Results from the application of consequential E-LCA show that the potential impact on climate change would be reduced by $414 \mathrm{~kg} \mathrm{CO} 2 / \mathrm{MWh}$ in the case of HYSOL BIO and $175 \mathrm{~kg}$ $\mathrm{CO}_{2} / \mathrm{MWh}$ in the case of HYSOL NG. The weighted environmental impact (single score) would be reduced by $59.8 \mathrm{pt}$ and $21.5 \mathrm{pt}$ per MWh produced (by HYSOL BIO and HYSOL NG, respectively). Meeting the targets for CSP in Spain described in the National Plan for Renewable Energies through the installation of 12 HYSOL plants (as considered in Sect. 3.1.2) would reduce climate change emissions by $1.68 \mathrm{Mt} \mathrm{CO}_{2} /$ year in the case of HYSOL GN and by 3.97 $\mathrm{Mt} \mathrm{CO}_{2} /$ year in the case of HYSOL BIO.

c. Is the environmental impact of HYSOL technology lower than that of conventional CSP plants? Table 4 shows that HYSOL $\mathrm{BIO}$ achieved better results in all four environmental indicators than CSP PTC. Conversely, HYSOL NG showed worse environmental performance than CSP PTC in every indicator except for water stress, due to the dry cooling technology assumed in the former (compared to wet cooling in the latter). However, it is worth noting that the CSP PTC technology considered in this investigation (representing the most widely used in Spain) does not provide the same function as the HYSOL technology, since it has a lower generation capacity (in terms of capacity factor) and reduced dispatchability (ability to generate on demand). When considering a CSP power plant (either parabolic though or tower) with similar dispatchability than the HYSOL power plant (which implies higher NG hybridization), the environmental impacts of conventional CSP plants are higher than that of HYSOL technology for every scenario.

\subsection{Economic dimension}

d. What is the life cycle cost of producing electricity using HYSOL technology in Spain from the perspective of the owner of the power plant? The life cycle cost of electricity produced using HYSOL technology was calculated using LCC methodology as follows: $211 € / M W h$ for HYSOL $\mathrm{BIO}$ and $154 € / \mathrm{MWh}$ for HYSOL NG. The lower cost of HYSOL BIO relates to the fact that biomethane is currently more costly to generate than the market price of natural gas. The cost balance per functional unit for HYSOL BIO is negative ( $-12.6 € / \mathrm{MWh})$, meaning that the production of electricity using this technology is not profitable for the perspective of the plant owner. However, the cost balance of the HYSOL NG plant was positive (6.33 €/MWh), meaning that the technology generates benefits in excess of the expected return on the investment.

e. Is the life cycle cost of HYSOL electricity lower than that of conventional CSP plants? The life cycle cost of electricity generation in the conventional CSP PTC plant (192 $€ / \mathrm{MWh}$ ) was $20 \%$ higher than HYSOL NG but $9.9 \%$ lower than HYSOL BIO. The improved economic performance of HYSOL NG technology is due to its higher energy efficiency (compared to conventional CSP), while the lower performance of the HYSOL BIO technology is due to the higher cost associated with the use of biomethane (compared to natural gas).

f. What is the effect of HYSOL life cycle on the global generation of goods and services, and value added? The total generation of goods and services throughout the life cycle of the HYSOL BIO and HYSOL NG systems was calculated to amount to $529 € / \mathrm{MWh}$ and $330 € / \mathrm{MWh}$, respectively. The global value added accumulated in the supply chain (due to the indirect economic activity) represents $44.4 \%$ and $43.0 \%$ of the total value of G\&S generated in HYSOL BIO and HYSOL NG, respectively. The global multiplier effect, measuring the capacity of the technologies to generate indirect G\&S, was determined to amount to 2.42 and 2.48 , respectively. The differences observed between the two HYSOL systems may be attributed to the higher value added generated by the life cycle of biomethane, compared to natural gas.

g. What changes are expected in the global generation of goods and services, and of value added as a result of introducing the HYSOL technology into the electricity market? The MRIO analysis, conducted using a net approach (i.e. considering displacement of other electricity technologies as a result of introducing solar power),
Table 4 Potential environmental impacts of HYSOL technology compared to CSP technology in the four main environmental indicators (consequential approach)

\begin{tabular}{llllll}
\hline & & $\begin{array}{l}\text { Climate change } \\
(\mathrm{kg} \mathrm{CO} \text { eq/MWh })\end{array}$ & $\begin{array}{l}\text { Water stress } \\
\left(\mathrm{m}^{3} / \mathrm{MWh}\right)\end{array}$ & $\begin{array}{l}\text { EPBT } \\
(\text { months })\end{array}$ & $\begin{array}{l}\text { Single score } \\
\text { environmental impact } \\
(\mathrm{pt} / \mathrm{MWh})\end{array}$ \\
\hline HYSOL & BIO & -414 & 0.164 & 6.1 & -59.8 \\
\multicolumn{2}{l}{ CSP PTC $(15 \% \mathrm{NG})$} & -333 & 0.151 & 22 & -21.5 \\
\hline
\end{tabular}


concluded that the deployment of HYSOL BIO increased the generation of G\&S and value added in Spain by 145 $€ / \mathrm{MWh}$ and $88 € / \mathrm{MWh}$, respectively. The deployment of HYSOL NG would cause a $24.8 € / \mathrm{MWh}$ reduction in the generation of G\&S in Spain but a 6.27€/MWh increase in value added. However, when considering net effects for the global economy, the results indicated a decrease in both global G\&S generation and global value added. These results suggest that HYSOL technology would increase macro-economic benefits in Spain at the expense of foreign economies.

\subsection{Social dimension}

h. Does HYSOL technology promote employment creation in the Spanish electricity sector? Net employment generated in Spain due to the deployment of HYSOL technology in the Spanish electricity market (according to the scenario defined in Sect. 2.1.2) resulted in the creation of 454,090 person-year for HYSOL BIO and 158,106 person-year for HYSOL NG.

i. What are the social risks of the HYSOL technology supply chain? Weighted social risks associated with HYSOL technology amount to $0.45 \mathrm{pt} / \mathrm{MWh}$ when using biomethane as auxiliary fuel (HYSOL BIO) and $1.26 \mathrm{pt} /$ MWh when using natural gas (HYSOL NG). The higher value observed in the latter scenario is due to increased social risks associated with the provision of NG, primarily imported from Algeria. In Spain, the social risks associated with the life cycle of HYSOL plants are related to gender inequality, corruption, labour injuries and immigrants, as determined by applying the economic inventory of the technology to the Social Hotspots Database (SHDB).

j. Is the employment generation and social risk of HYSOL electricity lower than that of conventional CSP PTC plants? Net employment generated by conventional CSP PTC plants in Spain amounts to $4.6 \mathrm{~h} / \mathrm{MWh}$, which is higher than the values calculated for HYSOL BIO $(3.3 \mathrm{~h} /$ $\mathrm{MWh}$ ) and HYSOL NG (1.2 h/MWh) plants. This reduced employment generation (per functional unit) observed in HYSOL plants is mainly associated with the higher energy efficiency achieved by this novel technology, which requires the same number of workers in the O\&M phase for a higher electricity output.

The social risk of HYSOL GN (1.26 pt/MWh) is higher than that of CSP PTC ( $0.96 \mathrm{pt} / \mathrm{MWh})$ due to the reduced solar fraction of the former and the high social risk associated with natural gas imported from Algeria. However, the social risk of HYSOL BIO is lower than that of CSP PTC $(0.45 \mathrm{pt} / \mathrm{MWh})$ due to the reduced social impacts associated with the biomethane (compared to natural gas). k. Does the life cycle of HYSOL technology improve social conditions in Spain? The S-LCA shows that the life cycles of HYSOL power plants (BIO and NG) both have positive effects on labour rights, safe and safety, cultural and natural heritage, fair relations and socio-economic sustainability of workers, local communities, society and value chain actors. This is because the promoter and operator of these plants have been considered to perform better in social terms than the Spanish average. This positive effect is especially relevant for the society stakeholder and the "socio-economic sustainability" category, while the "labour rights and decent work" category is the one benefiting the least. Hence, the deployment of HYSOL $\mathrm{BIO}$ and HYSOL NG would both result in a slight benefit of social welfare in Spain. The aggregated score of social performance amounts to 0.416 points, which lays between the values for "similar performance than the average" (= $0)$ and "better performance than the average" (=1).

\subsection{Presentation of results for decision making}

The secondary goal of the study is to provide a response to the question: "In the context of a future Spanish renewable energy plan, which CSP technology should be favoured considering sustainability criteria?". To facilitate the selection of the most suitable technology, Fig. 3 illustrates the sustainability crowns defined for each of the three alternative technologies considered in the LCSA. Since the sustainability crowns are intended for comparative purposes, only the consequential results from the E-LCA analyses and the net values from the MRIO analyses were used to represent the indicators climate change, single score and value added. As observed in the diagrams, HYSOL BIO produced the best results in terms of environmental and social performance, with all the indicators marked in green, representing performance better than average (except for social performance, which produced the same value in all the alternatives). However, this technology produced the worst results with regard to economic performance, particularly in the indicator cost balance.

The substitution of biomethane with natural gas in HYSOL NG penalized the environmental and social performance of the technology, as demonstrated by the predominance of reddish colours in the environmental and social sectors of the sustainability crowns. The only exception is water stress, due to the higher water demands generated by the biomethane life cycle. In contrast, the HYSOL NG technology exhibited improved economic performance primarily due to superior cost balances and life cycle costs.

Conventional CSP PTC performed slightly better than average in all the environmental indicators (except for water stress due to use of wet cooling instead of dry cooling in the Rankine cycle) and very similar to average in the social 
dimension. Conventional CSP PTC performed worse than HYSOL BIO but better than HYSOL GN in the environmental and social indicators, while the opposite was observed in the economic dimension.

The results described in this section show that none of the solar power alternatives performed best in all the sustainability dimensions and indicators evaluated. Hence, selection of the most sustainable alternative is not straightforward, requiring the application of some kind of multi-criteria decision making (MCDM) analysis. The use of analytic hierarchy process (AHP) would be facilitated by the use of the sustainability crowns described above, which could be used by stakeholders to interpret the results obtained in the LCSA.

\section{Conclusions}

This paper responds to the need expressed by the LCA community to test the practical application of life cycle-based sustainability assessment on different products and services following a scientific, systematic and quantitative approach. The described case study investigates the use of LCSA to evaluate the sustainability of deploying a novel hybrid solar power technology (HYSOL) in Spain. The methodology employed in this analysis builds upon the LCSA (analysis) framework developed in the CALCAS project. Despite its narrower acceptance, this framework provides more flexibility in the identification of objectives, definition of scope and selection of analysis, and aggregation tools than the more conventional LCSA (assessment) framework proposed by UNEP/SETAC. This makes it more suitable to adapt to the needs of specific products, enclose the complexity of real systems and adjust to the interdependences between the three sustainability dimensions (economic, social and environmental).

Regarding the application of LCSA (analysis) to evaluate the sustainability of HYSOL technology, this case study demonstrates the usefulness of using sustainability questions and sub-questions to define general and specific objectives of the analysis, outline its scope, select the most appropriate analysis tools and devise the means to draw together and communicate the results. The analysis tools selected in this case study extend beyond those proposed by LCSA (assessment) approach (LCA, LCC and S-LCA), including also attributional and consequential E-LCA, LCC, MRIO, Social Hotspots Analysis and S-LCA. MRIO analysis was useful at quantifying the socio-economic performance of the product from a society perspective instead of only from a private or partial perspective. The consequential approach used in E-LCA (considering technologies displaced by the introduction of HYSOL technology), the net approach used in MRIO and the relative approach in S-LCA (comparing social performance of HYSOL against the average in the sector) were useful at quantifying the sustainability effect of the system at a meso level.
The need to use a wider range of analysis tools in this case study was found to be time consuming and required the involvement (or training) of practitioners covering a wider range of skills. However, once the goal, scope and inventory steps of the framework were defined, the application of the analysis tools was straightforward. As with conventional LCA methodologies, the most time-consuming phase was collecting primary inventories and adapting the data to existing databases (i.e. ecoinvent and others for LCA, WIOD for MRIO, SHDB and international statistics for S-LCA).

Regarding the interpretation step, the use of weighting and aggregating procedures to generate a single indicator that incorporates all three sustainability dimensions would lead to information losses and increased uncertainty. However, aggregation of results may still be required for decision making when comparing with alternative products or services. In such cases, providing that the alternatives have been assessed using exactly the same methodology and scope, multi-criteria decision-making methods (i.e. analytic hierarchy process with participation of stakeholder representatives) may be useful to define weighing factors prior to aggregation. This exercise may be facilitated using circular diagrams (sustainability crowns) that provide a visual representation of the sustainability profile of the system as determined in the LCSA. These simplified diagrams should be accompanied by a report providing complete information about methodological aspects of the analysis, including sensitivity analyses, uncertainty and methodological limitations of the results.

The application of the LCSA (analysis) framework to the HYSOL technology revealed significant differences depending on the type of hybridization fuel. The use of biomethane improved the environmental, economic (at meso level) and social sustainability of the system compared to natural gas, but reduced its economic performance at a company (micro) level. When comparing HYSOL with conventional CSP, the results evidenced that the innovations achieved by HYSOL technology would also redound to the sustainability of the Spanish electricity sector (when comparing to a CSP plant with the same electricity production and dispatchability).

The influence of time in this study has only been contemplated in the economic dimension via discount rates for inflation, opportunity risks and future changes in fuel costs. This is an important limitation considering that the technology would be deployed in the future. The use of a dynamic approach taking into account the timing of emissions, future changes in technologies and climate, markets evolution and social trends in the medium term would certainly enrich the results and the conclusions of the analysis, and it is highly recommended as a means to improve this methodological proposal. This study would also be improved with the inclusion of an AHP method in the decision making step. Although this final step was not performed, all the recommendations and necessary information is provided in Sect. 2.3. 
Acknowledgments We also thank the reviewers for their valuable comments and suggestions.

Funding information This HYSOL project was funded by the European Commission: Innovative Configuration for a Fully Renewable Hybrid CSP Plant FP7-ENERGY-2012-1 CP 308912.

Open Access This article is distributed under the terms of the Creative Commons Attribution 4.0 International License (http:// creativecommons.org/licenses/by/4.0/), which permits unrestricted use, distribution, and reproduction in any medium, provided you give appropriate credit to the original author(s) and the source, provide a link to the Creative Commons license, and indicate if changes were made.

Publisher's Note Springer Nature remains neutral with regard to jurisdictional claims in published maps and institutional affiliations.

\section{References}

Benoit-Norris C, Norris GA, Aulisio D (2013) The social hotspots database V2. New Earth

Brundtland GH (1987) Report of the World Commission on environment and development: "our common future". United Nations. http:// www.un-documents.net/our-common-future.pdf. Accessed 3 December 2018

Cinelli M, Coles SR, Jørgensen A, Zamagni A, Fernando C, Kirwan K (2013) Workshop on life cycle sustainability assessment: the state of the art and research needs-November 26, 2012, Copenhagen, Denmark. Int J Life Cycle Assess 18:1421-1424

Ciroth A, Finkbeier M, Hildenbrand J, Klöpffer W, Mazijn B, Prakash S, Sonnemann G, Traverso M, Ugaya CML, Valdivia S (2011) Towards a life cycle sustainability assessment: making informed choices on products. UNEP. https://www.lifecycleinitiative.org/wpcontent/uploads/2012/12/2011\%20-\%20Towards\%20LCSA.pdf. Accessed 3 December 2018

Corona Bellostas B (2016) Análisis de sostenibilidad del ciclo de vida de una configuración innovadora de tecnología termosolar. Doctoral dissertation [in Spanish]. Dissertation or Thesis, Industriales

Corona B, de la Rúa C, San Miguel G (2016a) Socio-economic and environmental effects of concentrated solar power in Spain: a multiregional input output analysis. Sol Energy Mater Sol Cells 156: 112-121. https://doi.org/10.1016/j.solmat.2016.03.014

Corona B, San Miguel G, Cerrajero E (2014) Life cycle assessment of concentrated solar power (CSP) and the influence of hybridising with natural gas. Int J Life Cycle Assess 19(6):1264-1275

Corona B, Bozhilova-Kisheva KP, Olsen SI, San Miguel G (2017) Social life cycle assessment of a concentrated solar power plant in Spain: a methodological proposal. J Ind Ecol 21:1566-1577

Corona B, Ruiz D, San Miguel G (2016b) Life cycle assessment of a HYSOL concentrated solar power plant: analyzing the effect of geographic location. Energies 9:413

Corona B, Cerrajero E, López D, San Miguel G (2016c) Full environmental life cycle cost analysis of concentrating solar power technology: contribution of externalities to overall energy costs. Sol Energy 135:758-768

European Commission (2003) Communication from the commission to the Council and the European Parliament. Integrated product policy, building on environmental life-cycle thinking. Brussels, 18.6.2003 $\operatorname{COM}(2003) 302$ final. https://eur-lex.europa.eu/legal-content/en/ TXT/?uri=CELEX\%3A52003DC0302. Accessed 3 December 2018

Finkbeiner M, Schau EM, Lehmann A, Traverso M (2010) Towards life cycle sustainability assessment. Sustainability 2:3309-3322
Goedkoop M, Heijungs R, Huijbregts M, De Schryver A, Struijs J, van Zelm R (2009) ReCiPe 2008. A life cycle impact assessment method which comprises harmonised category indicators at the midpoint and the endpoint level 1. http://rivm.openrepository.com/rivm/ handle/10029/620793. Accessed 3 December 2018

Grießhammer R, Buchert M, Gensch C, Hochfeld C, Manhart A, Rüdenauer I, Ebinger F (2007) PROSA — product sustainability assessment. Beschreibung der Methode. http:/www.prosa.org/ fileadmin/user_upload/pdf/PROSA-gesamt_Finalversion_0407 red.pdf. Accessed 3 December 2018

Guinee JB, Heijungs R, Huppes G, Zamagni A, Masoni P, Buonamici R, Ekvall T, Rydberg T (2010) Life cycle assessment: past, present, and future†. Environ Sci Technol 45:90-96

Hardi P, Semple P (2000) The Dashboard of Sustainability: from a metaphor to an operational set of indices. Paper presented at the Fifth International Conference on Social Science Methodology. Cologne, Germany, October 3-6, 2000

Heijungs R, Huppes G, Guinée J (2009) A scientific framework for LCA - deliverable (d15) of work package 2 (wp2) CALCAS project. Institute of Environmental Sciences, Leiden University (CML). https://www.researchgate.net/publication/232770143_A_ scientific framework for LCA. Accessed 3 December 2018

Hischier R, Weidema B, Althaus H, Bauer C, Doka G, Dones R, Frischknecht R, Hellweg S, Humbert S, Jungbluth N (2010) Implementation of life cycle impact assessment methods. Ecoinvent report. http://esu-services.ch/fileadmin/download/ publicLCI/03 LCIA-Implementation.pdf. Accessed 3 December 2018

Hu M, Kleijn R, Bozhilova-Kisheva KP, Di Maio F (2013) An approach to LCSA: the case of concrete recycling. Int J Life Cycle Assess 18: 1793-1803

Hunkeler D, Lichtenvort K, Rebitzer G (2008) Environmental life cycle costing. CRC Press, Boca Ratón

IDAE (2011) Plan de Energías Renovables (PER) 2010-2020. www.idae. es/file/9712/download?token=6MoeBdCb. Accessed 3 December 2018

Jesinghaus $J$ (2000) On the art of aggregating apples \& oranges. Fondazione Eni Enrico Mattei Milan. https://www.econstor.eu/ bitstream/10419/155144/1/NDL2000-091.pdf. Accessed 3 December 2018

Jorgensen A, Herrmann IT, Bjorn A (2013) Analysis of the link between a definition of sustainability and the life cycle methodologies. Int $\mathrm{J}$ Life Cycle Assess 18:1440-1449

Kloepffer W (2008) Life cycle sustainability assessment of products. Int J Life Cycle Assess 13:89-94

Mathiesen BV, Münster M, Fruergaard T (2009) Uncertainties related to the identification of the marginal energy technology in consequential life cycle assessments. J Clean Prod 15:1331-1338

Neugebauer S, Martinez-Blanco J, Scheumann R, Finkbeiner M (2015) Enhancing the practical implementation of life cycle sustainability assessment - proposal of a tiered approach. J Clean Prod 102:165176

Nzila C, Dewulf J, Spanjers H, Tuigong D, Kiriamiti H, van Langenhove $\mathrm{H}$ (2012) Multi criteria sustainability assessment of biogas production in Kenya. Appl Energy 93:496-506

Onat NC, Kucukvar M, Tatari O (2014) Integrating triple bottom line input-output analysis into life cycle sustainability assessment framework: the case for US buildings. Int J Life Cycle Assess 19:14881505

Orden IET/1045/2014 (2014) Orden IET/1045/2014, de 16 de junio, por la que se aprueban los parámetros retributivos de las instalaciones tipo aplicables a determinadas instalaciones de producción de energía eléctrica a partir de fuentes de energía renovables, cogeneración y residuos. BOE-A-2014-6495. BOE-A-2014-6495; 140:46430-48190 
Peukert B, Benecke S, Clavell J, Neugebauer S, Nissen NF, Uhlmann E, Lang K, Finkbeiner M (2015) Addressing sustainability and flexibility in manufacturing via smart modular machine tool frames to support sustainable value creation. Procedia CIRP 29:514519. https://doi.org/10.1016/j.procir.2015.02.181

Pfister et al (2012) Water Stress Index (Pfister et al. 2009). In: https:// www.google.es/url?sa=t\&rct=j\&q=\&esrc=s\&source=web\&cd= $1 \& \mathrm{c}$ a $\mathrm{d}=\mathrm{r} \mathrm{j}$ a $\&$ u a $\mathrm{c} \mathrm{t}=8 \& \mathrm{v}$ e $\mathrm{d}=$ 0ahUKEwj3593pruXJAhVJ2BoKHXfKDDkQFggfMAA\&url= http $\% 3 \mathrm{~A} \% 2 \mathrm{~F} \% 2 \mathrm{Fwww}$. ifu.ethz.ch $\% 2 \mathrm{Fstaff} \% 2 \mathrm{Fstpfiste} \%$ 2FImpact_factors_LCA_pfister_et_al.kmz\&usg=AFQjCNEN 69 B 6 D y D 7 s b $3 \mathrm{~K} \mathrm{~W}$ _C ix e o 4 P P W - A \& s i g $2=5$ iVAOZBPtZnpiUA0xQOkA \&bvm=bv.110151844,d.ZWU. Accessed 04/12 2015

Real Decreto 413/2014 (2014) Real Decreto 413/2014, de 6 de junio, por el que se regula la actividad de producción de energía eléctrica a partir de fuentes de energía renovables, cogeneración y residuos. BOE-A-2014-6123; 140:43876-43978. https://www.boe.es/buscar/ doc.php?id=BOE-A-2014-6123. Accessed 3 December 2018

Saaty TL (1990) How to make a decision: the analytic hierarchy process. Eur J Oper Res 48:9-26

Sala S, Farioli F, Zamagni A (2013) Life cycle sustainability assessment in the context of sustainability science progress (part 2). Int J Life Cycle Assess 18:1686-1697

San Miguel G, Corona B, Ruiz D (2016) D6.3 full life cycle analysis of HYSOL technology: environmental and socio-economic assessment. HYSOL project:1-165. http://www.hysolproject.eu/docs/ HYSOL_D6.3_LCA.pdf. Accessed 3 December 2018

San Miguel G, Corona B, Servert J, López D, Cerrajero E, Gutierrez F, Lasheras M (2015) Technical and environmental analysis of parabolic trough concentrating solar power (CSP) technologies. In: Lefebre G, Jiménez E, Cabañas B (eds) Environment, Energy and Climate Change II. Springer International Publishing, Cham, p 3353

Schepelmann P, Ritthoff M, Santman P, Jeswani H, Azapagic A (2008) Report on the SWOT analysis of concepts, methods and models potentially supporting LCA-deliverable (d10) of work package 3 (WP3) CALCAS project. Wuppertal Institute for Climate and Energy and School of Chemical Engineering and Analytical Science, University of Manchester

Servert JF, Cerrajero E, López D, Yagüe S, Gutierrez F, Lasheras M, Miguel GS (2015) Base case analysis of a HYSOL power plant. Energy Procedia 69:1152-1159
Timmer M, Erumban A, Gouma R, Los B, Temurshoev U, de Vries G, Arto I (2012) The world input-output database (WIOD): contents, sources and methods. WIOD background document available at www.wiod.org. Accessed 3 December 2015

Timmer MP, Dietzenbacher E, Los B, Stehrer R, Vries GJ (2015) An illustrated user guide to the world input-output database: the case of global automotive production. Rev Int Econ 23:575-605

Traverso M, Finkbeiner M, Jorgensen A, Schneider L (2012) Life cycle sustainability dashboard. J Ind Ecol 16:680-688

UNEP/SETAC (2015) Life Cycle Initiative. In: . http://www. lifecycleinitiative.org/. Accessed 08/27 2015

UNEP/SETAC Life Cycle Initiative (2009) Guidelines for social life cycle assessment of products. United Nations Environment Programme ISBN:978-992. https:/www.lifecycleinitiative.org/wpcontent/uploads/2012/12/2009\%20-\%20Guidelines $\% 20$ for\% 20sLCA\%20-\%20EN.pdf. Accessed 3 December 2018

Wang J, Jing Y, Zhang C, Zhao J (2009) Review on multi-criteria decision analysis aid in sustainable energy decision-making. Renew Sust Energ Rev 13:2263-2278

Weidema BP, Bauer C, Hischier R, Mutel C, Nemecek T, Reinhard J, Vadenbo C, Wernet G (2013) The ecoinvent database: overview and methodology, Data quality guideline for the ecoinvent database version 3. www.ecoinvent.org. Accessed 3 December 2018

Wolf M, Chomkhamsri K, Brandao M, Pant R, Ardente F, Pennington DW, Manfredi S, de Camillis C, Goralczyk M (2010) ILCD Handbook-General Guide for Life Cycle Assessment-Detailed Guidance. http://eplca.jrc.ec.europa.eu/uploads/ILCD-HandbookGeneral-guide-for-LCA-DETAILED-GUIDANCE-12March2010ISBN-fin-v1.0-EN.pdf. Accessed 3 December 2018

Wood R, Hertwich EG (2013) Economic modelling and indicators in life cycle sustainability assessment. Int J Life Cycle Assess 18:1710 1721

Zamagni A, Buttol P, Buonamici R, Masoni P, Guinée J, Huppes G, Heijungs R, van der Voet E, Ekvall T, Rydberg T (2009) Blue paper on life cycle sustainability analysis; deliverable 20 of the CALCAS project, 2009. Available at www.calcasproject.net

Zamagni A, Pesonen H, Swarr T (2013) From LCA to Life Cycle sustainability assessment: concept, practice and future directions. Int J Life Cycle Assess 18:1637-1641

Zamagni A (2012) Life cycle sustainability assessment. Int J Life Cycle Assess 17:373-376 